\title{
Radial artery grafting in women improves 15-year survival
}

\author{
Kamellia R. Dimitrova, MD, Darryl M. Hoffman, MD, Charles M. Geller, MD, Wilson Ko, MD, \\ David J. Lucido, PhD, Gabriela R. Dincheva, and Robert F. Tranbaugh, MD
}

\begin{abstract}
Objectives: Radial artery (RA) grafting has a clear survival advantage after coronary artery bypass grafting (CABG) in studies with predominantly male populations, but the impact on women's long-term survival is unclear. We sought to determine if the reported long-term survival benefit of RA versus saphenous vein (SV) grafting in the general $\mathrm{CABG}$ population is valid for women.
\end{abstract}

Methods: Between 1995 and 2010, 1339 female patients were alive 30 days after primary, isolated CABG with left internal thoracic artery (LITA) and additional RA or SV conduits as needed. Patients were evaluated based on RA use: 332 patients had RA and 1007 patients had SV. Of these, 283 RA patients were matched to SV counterparts using a nonparsimonious propensity model based on 45 patient variables.

Results: Kaplan-Meier estimated survivals for the matched RA women at 1, 5, 10, and 15 years were 99\%, 93\%, $80 \%$, and $70 \%$ versus $97 \%, 87 \%, 72 \%$, and $58 \%$ for the SV women (log rank, $P=.018$ ). For symptomatic patients, overall RA patency was $80 \%$, which was not different from the LITA patency rate of $84 \%$ but was superior to the SV conduits patency rate of $56 \%(P<.001)$.

Conclusions: In women undergoing CABG with LITA grafting, use of an RA graft improves survival compared with use of an SV graft. (J Thorac Cardiovasc Surg 2013;146:1467-73)

Women have been reported to have increased hospital mortality and morbidity after coronary artery bypass grafting (CABG), in part attributed to referral bias, smaller coronary vessels, smaller body size, more advanced coronary artery disease, older age at presentation, markedly higher risk profile, higher transfusion rate, gender differences in molecular remodeling in pressure overload hypertrophy, and a higher incidence of metabolic syndrome. ${ }^{1}$ However, intermediate and long-term survivals have been reported to be better in women and the use of 2 or more arterial grafts in women is associated with improved long-term survival. ${ }^{2}$ Thus, the addition of a second arterial conduit may be an important determinate of survival in women after CABG.

Use of a radial artery (RA) conduit in addition to the left internal thoracic artery (LITA) improves patients' longterm survival after $\mathrm{CABG}^{3-7}$ In these reports, however, only $10 \%$ to $23 \%$ of the study populations were women, and it is unclear whether, and to what extent, this observed RA survival benefit extends to women. In our previous report, ${ }^{3}$ we were not able to show a survival benefit for RA grafting in women compared with men in

\footnotetext{
From the Division of Cardiac Surgery, Beth Israel Medical Center, New York, NY. This study was supported by funds from the Division of Cardiac Surgery at the Beth Israel Medical Center, New York, New York.

Disclosures: Authors have nothing to disclose with regard to commercial support. Received for publication Aug 3, 2012; revisions received Sept 14, 2012; accepted for publication Oct 2, 2012; available ahead of print Nov 5, 2012

Address for reprints: Kamellia R. Dimitrova, MD, Division of Cardiac Surgery, Beth Israel Medical Center, 317 East 17th St, Fierman Building, 11th Floor, New York, NY 10003 (E-mail: kdimitrova2@chpnet.org). $0022-5223 / \$ 36.00$

Copyright (c) 2013 by The American Association for Thoracic Surgery http://dx.doi.org/10.1016/j.jtcvs.2012.10.004
}

a secondary analysis. However, women comprised only $17 \%$ of our patients and there were very few patients at risk after 8 years. Thus, in this study, we specifically sought to determine the effect of RA grafting on long-term survival after CABG in women by comparing propensity-matched women revascularized with LITA and RA versus women receiving LITA and only saphenous vein (SV) grafts.

\section{METHODS \\ Patients}

From January 1995 to December 2010, 1367 women had isolated, primary CABG with LITA and additional grafts as needed after excluding patients with single CABG $(n=4)$, only SV grafts $(n=8)$, or only bilateral internal thoracic artery (BITA) grafts $(n=9)$. At 30 days, 1339 women were alive and were included in the analysis. Of these, 332 patients received an RA conduit (RA group), and 1007 received SV conduits. The primary factors involved in the decision to use an RA conduit included the result of the Allen test, perceived patient lifespan (patients $<65$ years), nonemergency nature of the operation, and a target vessel stenosis of at least $70 \%$. Unavailable or unsuitable SV conduits accounted for RA use in older patients. Most RA grafts were used to bypass the circumflex $(73 \%)$ and diagonal $(21 \%)$ arteries. Only $6 \%$ received an RA to the right coronary artery. Renal failure was considered a contraindication for RA harvest owing to concern for the need for possible upper limb dialysis access.

All data were prospectively collected as part of the New York State Department of Health mandatory reporting system and maintained in a separate database at our institution. Institutional review board approval was obtained and written informed consent was waived.

\section{Graft Patency}

The New York State Department of Health Cardiac Surgery Reporting System and the Percutaneous Coronary Intervention Reporting System databases were used to identify patients who had undergone coronary reintervention after $\mathrm{CABG}$ in our institution. Symptom driven after CABG angiograms was identified and analyzed by 2 observers independently. 


$$
\begin{aligned}
& \text { Abbreviations and Acronyms } \\
& \text { BITA }=\text { bilateral internal thoracic artery } \\
& \text { CABG }=\text { coronary artery bypass grafting } \\
& \text { CI }=\text { confidence interval } \\
& \text { HR }=\text { hazard ratio } \\
& \text { LITA }=\text { left internal thoracic artery } \\
& \text { RA }=\text { radial artery } \\
& \text { SV }=\text { saphenous vein }
\end{aligned}
$$

\section{Surgical Technique}

CABG was mostly performed using cold blood cardioplegic arrest and a single period of aortic crossclamping. RAs were used as aorta-coronary bypasses and sequential or $\mathrm{Y}$ grafts. Off-pump procedures were performed in $2.5 \%$ of all patients $(2.6 \%$ of the SV patients and $0.9 \%$ of the RA patients) generally owing to an unclampable or heavily diseased ascending aorta. None of the propensity-matched patients had off-pump surgery. Before 1999, the RA was harvested using an open no-touch technique; since 2000, all RA conduits in our institution have been harvested exclusively using an endoscopic technique. The RA is readily harvested endoscopically via a small wrist incision. ${ }^{8}$ It is 15 to $25 \mathrm{~cm}$ long, easily reaches any vessel on the heart, and is a better size match to the native coronary arteries than is the SV. Sequential or Y grafting increases the number of arterial grafts per patient. Diltiazem is administered by intravenous infusion after induction of anesthesia and is continued until the first postoperative day, when oral nitrates or diltiazem is substituted and continued wherever possible for at least 6 months. Intraoperative Allen test and pulse oximetry were used to confirm adequate collateral blood flow to the hand. Less than $2 \%$ of screened RAs could not be harvested. No postoperative hand ischemia has been detected. A rare harvested RA had to be discarded because of unsuspected severe wall thickening or calcific disease. After division, the RA was cannulated at the proximal end and placed in a solution of $1 \%$ papaverine mixed with the patient's heparinized venous blood, which contains diltiazem.

\section{Statistical Methods}

All available risk factors (Table 1) were included in a nonparsimonious multivariable logistic regression model that predicted the probability of treatment with the RA rather than the SV conduit. ${ }^{9}$ On the basis of the number of grafts used for CABG, the year of CABG, and the value of the propensity score as a composite variable, RA patients were matched to SV patients using the nearest neighbor matching method. We compared the balance of all baseline characteristics in Table 1 before and after the matching using the standardized difference. Our model was well calibrated and discriminated effectively between RA and non-RA patients at baseline (c-statistic $=0.821)$. Patients on hemodialysis and with a creatinine level greater than $2.5 \mathrm{mg} / \mathrm{dL}$ ( 53 in the SV group and 3 in the RA) were excluded from the matching process.

Statistical analysis was performed with the Zelig/CRAN 2.14.01 (http:// cran.r-project.org) ${ }^{10}$ and XLSTAT software. Continuous variables were expressed as mean and standard deviation. Categorical variables were expressed as numbers and percentages. Dichotomous variables were analyzed using the $\chi^{2}$ test and Fisher's exact test, and continuous variables were analyzed using the $t$ test. The primary end point was all-cause mortality obtained using the Social Security Death Index, which was searched in May 2011. The overall difference in survival between RA and SV patients was estimated by comparing the Kaplan-Meier survival curves for the matched patients. The overall hazard ratios (HR) for death after CABG were obtained by fitting a Cox proportional hazards model, stratifying on the matched pairs of patients. Inasmuch as CABG is a factor influencing early death, the patients who died in the hospital or within 30 days after CABG were excluded from the matching and survival analysis.

Statistical analysis of graft patency was performed with STATA system version 12.1 (StataCorp LP, College Station, Tex). The primary end point was graft failure, defined as graft occlusion or a $50 \%$ stenosis or greater. The Cox proportional hazard model was used to assess differences in the HR between groups defined by graft type. Because patients contributed 1 or more grafts to the analysis, robust standard errors and confidence limits for the HRs were achieved by adjusting for 244 female patients' clusters within the data.

\section{RESULTS}

\section{Demographic Characteristics}

Table 1 shows that unmatched RA women $(\mathrm{n}=332)$ compared with SV women $(n=1035)$ were younger (average age, 59.5 years vs 70 years), more obese (body mass index, 29.7 vs 27.7 ; body surface area, 1.83 vs 1.77 ), had higher ejection fractions (average, $54 \%$ vs $50 \%$ ), and fewer cases of preoperative myocardial infarction, chronic obstructive pulmonary disease, peripheral vascular disease, stroke, hypertension, and congestive heart failure (Table 1). Also, RA women were more likely to have diabetes ( $53 \%$ vs $47.5 \%)$, receive more grafts (average, 3.6 vs 3.4), and have longer crossclamp and bypass times.

Propensity matching yielded 283 pairs of women revascularized with either an RA or an SV. The propensity matching model was well calibrated. Table 1 shows that the standardized differences in the prevalence of all baseline characteristics between RA and SV women were all less than or equal to $2 \%$ and were not statistically different.

\section{Hospital Outcomes}

There were no hospital and 30-day deaths in the unmatched RA group and $28(2.7 \%)$ deaths in the SV group $(P<.0001)$. These hospital and early deaths were excluded from the propensity matching model and survival analysis. Table 1 shows that in the matched patients, rates of postoperative stroke, postoperative myocardial infarction, renal failure, and sternal wound infection were similar. There was a trend toward a higher incidence of respiratory failure in the SV group compared with the RA group $(P=.06)$.

\section{Long-Term Survival}

During the follow-up period, $70(25 \%)$ deaths were observed among the 283 matched SV patients and 48 $(17 \%)$ deaths among the 283 matched RA patients $(P=.023)$. Figure 1 shows that the Kaplan-Meier estimated survivals for the matched RA women at 1, 5, 10, and 15 years were $99 \%$ (confidence interval [CI], 98\%$100 \%$ ), 93\% (CI, 96\%-98\%), 80\% (CI, 72\%-87\%), and $70 \%$ (CI, 60\%-79\%) versus $97 \%$ (CI, 96\%-100\%), $87 \%$ (CI, 82\%-92\%), 72\% (CI, 63\%-80\%), and 58\% (CI, 38\%-65\%) for the SV women (log rank, $P=.018$ ).

The average survival time for the RA female patients after $\mathrm{CABG}$ was $13 \pm 0.3$ years (range, 12.2-13.8 years) and 
TABLE 1. Patients' baseline, operative, and postoperative characteristics

\begin{tabular}{|c|c|c|c|c|c|c|}
\hline & RA patients $(n=332)$ & SV patients $(n=1035)$ & $\boldsymbol{P}$ & $\begin{array}{c}\text { Matched RA } \\
\text { patients (283) }\end{array}$ & $\begin{array}{c}\text { Matched SV } \\
\text { patients (283) }\end{array}$ & $\boldsymbol{P}$ \\
\hline Propensity score & $0.457( \pm 0.23)$ & $0.191( \pm 0.18)$ & $<.0001$ & $0.409( \pm 0.17)$ & $0.399( \pm 0.15)$ & .808 \\
\hline Age (y) average & $59.5( \pm 9.1)$ & $70( \pm 9.2)$ & $<.0001$ & $61( \pm 8.6)$ & $61( \pm 8.8)$ & .841 \\
\hline$<50 \mathrm{y}$ (patients, $\%$ ) & $43(13 \%)$ & $28(2.7 \%)$ & $<.0001$ & $24(8.5 \%)$ & $24(8.5 \%)$ & 1.000 \\
\hline $50-59$ y (patients, $\%$ ) & $123(37 \%)$ & $112(4 \%)$ & $<.0001$ & $99(35 \%)$ & $97(34 \%)$ & .802 \\
\hline $60-69$ y (patients, \%) & $125(38 \%)$ & $354(35 \%)$ & .252 & $120(42 \%)$ & $122(43 \%)$ & .810 \\
\hline$\geq 70$ y (patients, $\%)$ & $41(12.3 \%)$ & $541(52 \%)$ & $<.0001$ & $40(14 \%)$ & $40(14 \%)$ & 1.000 \\
\hline BMI & $29.7( \pm 6.1)$ & $27.7( \pm 6.4)$ & $<.0001$ & $30.1( \pm 6.2)$ & $29.3( \pm 6.2)$ & .174 \\
\hline BSA & $1.83( \pm 2.22)$ & $1.77( \pm 2.20)$ & $<.0001$ & $1.83( \pm 2.22)$ & $1.81( \pm 2.22)$ & .293 \\
\hline Ejection fraction average & $54( \pm 11.4)$ & $50( \pm 12.3)$ & .011 & $50( \pm 11.5)$ & $50( \pm 12.0)$ & .744 \\
\hline$<20 \%$ & $5(1.5 \%)$ & $19(1.8 \%)$ & .691 & $4(1.4 \%)$ & $1(0.3 \%)$ & .178 \\
\hline $20 \%-29 \%$ & $9(2.7 \%)$ & $34(13.3 \%)$ & .602 & $8(2.8 \%)$ & $9(3.2 \%)$ & .806 \\
\hline $30 \%-39 \%$ & $33(10 \%)$ & $133(13 \%)$ & .158 & $30(11 \%)$ & $35(12 \%)$ & .501 \\
\hline $40 \%-49 \%$ & $57(17 \%)$ & $220(21 \%)$ & .107 & $57(20 \%)$ & $57(20 \%)$ & 1.000 \\
\hline$\geq 50 \%$ & $219(66 \%)$ & $589(57 \%)$ & .003 & $184(65 \%)$ & $180(64 \%)$ & .701 \\
\hline Missing & $9(2.7 \%)$ & $40(3.9 \%)$ & .325 & 0.000 & 0.000 & \\
\hline No. of grafts & $3.6( \pm 0.908)$ & $3.4( \pm 0.864)$ & .006 & $3.5( \pm 0.9)$ & $3.5( \pm 0.9)$ & 1.000 \\
\hline Years since surgery & $7.35( \pm 4.5)$ & $7.6( \pm 4.1)$ & .256 & $7.2( \pm 4.5)$ & $7.2( \pm 4.5)$ & 1.000 \\
\hline \multicolumn{7}{|l|}{ Ethnicity/race } \\
\hline Nonhispanic white & $130(40 \%)$ & $425(41 \%)$ & .952 & $110(39 \%)$ & $112(40 \%)$ & .695 \\
\hline Nonhispanic black & $63(19 \%)$ & $217(21 \%)$ & .435 & $59(21 \%)$ & $61(21.5 \%)$ & .803 \\
\hline Hispanic & $111(33 \%)$ & $331(32 \%)$ & .480 & $93(33 \%)$ & $90(32 \%)$ & .788 \\
\hline Other & $28(8 \%)$ & $62(6 \%)$ & .433 & $21(7.4 \%)$ & $20(7 \%)$ & .820 \\
\hline \multicolumn{7}{|l|}{ Priority } \\
\hline Elective & $70(21 \%)$ & $192(19 \%)$ & .308 & $60(21 \%)$ & $60(21 \%)$ & 1.000 \\
\hline Urgent & $232(70 \%)$ & $757(73 \%)$ & .504 & $200(71 \%)$ & $200(71 \%)$ & 1.000 \\
\hline Emergency & $30(9 \%)$ & $86(8 \%)$ & .700 & $23(8 \%)$ & $23(8 \%)$ & 1.000 \\
\hline \multicolumn{7}{|l|}{$\operatorname{CCS}(\%)$} \\
\hline Class I & $2(0.6 \%)$ & $13(4 \%)$ & .320 & $1(0.4 \%)$ & $5(1.8 \%)$ & .101 \\
\hline Class II & $13(4 \%)$ & $29(2.8 \%)$ & .307 & $8(2.8 \%)$ & $10(3.5 \%)$ & .633 \\
\hline Class III & $111(33 \%)$ & $279(27 \%)$ & .023 & $89(31 \%)$ & $85(30 \%)$ & .710 \\
\hline Class IV & $206(62 \%)$ & $714(69 \%)$ & .019 & $185(65 \%)$ & $183(65 \%)$ & .886 \\
\hline \multicolumn{7}{|l|}{ Diseased vessels } \\
\hline Isolated LMT & $5(1.5 \%)$ & $20(1.95 \%)$ & .614 & $4(1.4 \%)$ & $4(1.4 \%)$ & 1.000 \\
\hline TVD + LMT & $63(19 \%)$ & $208(20 \%)$ & .656 & $55(19 \%)$ & $51(18 \%)$ & .517 \\
\hline TVD no LMT & $222(67 \%)$ & $665(64 \%)$ & .385 & $150(53 \%)$ & $151(53 \%)$ & .864 \\
\hline DVD + LMT & $15(4.5 \%)$ & $92(8.9 \%)$ & .010 & $31(11 \%)$ & $33(12 \%)$ & .736 \\
\hline DVD no LMT & $47(14.2 \%)$ & $162(15.2 \%)$ & .510 & $42(15 \%)$ & $44(15.5 \%)$ & .732 \\
\hline Proximal LAD & $240(72 \%)$ & $750(72 \%)$ & .815 & $199(70 \%)$ & $203(72 \%)$ & .664 \\
\hline Mid/distal LAD & $230(69 \%)$ & $636(61 \%)$ & .064 & $192(68 \%)$ & $188(66 \%)$ & .432 \\
\hline RCA or PDA & $292(88 \%)$ & $867(84 \%)$ & .076 & $247(87 \%)$ & $245(86 \%)$ & .897 \\
\hline Circumflex or OM & $275(83 \%)$ & $849(82 \%)$ & .771 & $231(82 \%)$ & $234(83 \%)$ & .858 \\
\hline Previous MI & $135(41 \%)$ & $517(50 \%)$ & .003 & $116(41 \%)$ & $119(42 \%)$ & .798 \\
\hline 1-7 d previously & $26(7.8 \%)$ & $91(8.8 \%)$ & .586 & $20(7 \%)$ & $20(7 \%)$ & 1.000 \\
\hline 8-14 d previously & $21(6.3 \%)$ & $92(8.9 \%)$ & .140 & $19(6.7 \%)$ & $20(7 \%)$ & .850 \\
\hline $15-20 \mathrm{~d}$ previously & $2(0.6 \%)$ & $19(1.8 \%)$ & .112 & $2(0.07 \%)$ & $4(1.4 \%)$ & .789 \\
\hline$\geq 21 \mathrm{~d}$ previously & $86(26 \%)$ & $315(30.4 \%)$ & .115 & $75(26.5 \%)$ & $75(26.5 \%)$ & 1.000 \\
\hline Stroke & $22(6.7 \%)$ & $100(9.7 \%)$ & .092 & $21(7.4 \%)$ & $23(8 \%)$ & .754 \\
\hline Carotid disease & $35(10.5 \%)$ & $172(16.6 \%)$ & .007 & $33(11.7 \%)$ & $32(11 \%)$ & .895 \\
\hline Aortoiliac PVD & $6(1.8 \%)$ & $37(3.6 \%)$ & .109 & $5(1.8 \%)$ & $4(1.4 \%)$ & .737 \\
\hline Femoropopliteal PVD & $31(9.3 \%)$ & $94(9.1 \%)$ & .888 & $27(9.5 \%)$ & $27(9.5 \%)$ & 1.000 \\
\hline Unstable hemodynamics & $3(1 \%)$ & $15(1.5 \%)$ & .448 & $2(0.7 \%)$ & $5(1.8 \%)$ & .255 \\
\hline Hypertension & $241(73 \%)$ & $839(81 \%)$ & .001 & $214(76 \%)$ & $214(76 \%)$ & 1.000 \\
\hline On IV NTG before CABG & $24(7.2 \%)$ & $168(16 \%)$ & $<.0001$ & $20(7 \%)$ & $17(6 \%)$ & .611 \\
\hline Current CHF & $28(8.4 \%)$ & $200(19.3 \%)$ & $<.0001$ & $27(10 \%)$ & $32(11 \%)$ & .687 \\
\hline
\end{tabular}


TABLE 1. Continued

\begin{tabular}{|c|c|c|c|c|c|c|}
\hline & RA patients $(\mathbf{n}=\mathbf{3 3 2})$ & SV patients $(n=1035)$ & $\boldsymbol{P}$ & $\begin{array}{c}\text { Matched RA } \\
\text { patients (283) }\end{array}$ & $\begin{array}{c}\text { Matched SV } \\
\text { patients (283) }\end{array}$ & $P$ \\
\hline COPD & $85(25.6 \%)$ & $391(37.8 \%)$ & $<.0001$ & $77(27.2 \%)$ & $77(27.2 \%)$ & 1.000 \\
\hline Ascending aorta atherosclerosis & $8(2.4 \%)$ & $88(8.5 \%)$ & $<.001$ & $7(2.4 \%)$ & $11(4 \%)$ & 1.000 \\
\hline Diabetes & $176(53 \%)$ & $492(47.5 \%)$ & .083 & $151(53 \%)$ & $155(55 \%)$ & .736 \\
\hline PCI before & $49(15 \%)$ & $137(13.2 \%)$ & .482 & $37(13 \%)$ & $50(18 \%)$ & .130 \\
\hline No renal failure* & $329(99 \%)$ & $982(95 \%)$ & .001 & $283(100 \%)$ & $283(100 \%)$ & 1.000 \\
\hline Crossclamp time (min) & $70( \pm 21.3)$ & $60( \pm 20.5)$ & $<.0001$ & $68( \pm 21.1)$ & $61( \pm 21.1)$ & $<.001$ \\
\hline $\mathrm{CPB}$ time (min) & $92( \pm 27)$ & $83( \pm 31)$ & $<.0001$ & $91( \pm 26.8)$ & $85( \pm 28.1)$ & .009 \\
\hline \multicolumn{7}{|c|}{ Thirty-day postoperative complications } \\
\hline Permanent stroke & $2(0.6 \%)$ & $13(1.3 \%)$ & .320 & $2(0.7 \%)$ & $1(0.4 \%)$ & .563 \\
\hline Postoperative MI & $3(1 \%)$ & $13(1.3 \%)$ & .604 & $3(1 \%)$ & $5(1.8 \%)$ & .477 \\
\hline Sternal wound infection & $8(2.4 \%)$ & $20(1.9 \%)$ & .594 & $7(2.5 \%)$ & $3(1 \%)$ & .203 \\
\hline Reoperation for bleeding & $3(1 \%)$ & $17(1.6 \%)$ & .330 & $2(0.7 \%)$ & $4(1.4 \%)$ & .413 \\
\hline Septicemia & $6(1.8 \%)$ & $27(2.6 \%)$ & .408 & $5(1.8 \%)$ & $2(0.7 \%)$ & .255 \\
\hline Renal Failure & $4(1.2 \%)$ & $30(2.9 \%)$ & .085 & $3(1 \%)$ & $4(1.4 \%)$ & .704 \\
\hline Respiratory failure & $7(2.1 \%)$ & $63(6.1 \%)$ & .004 & $7(2.5 \%)$ & $16(5.7 \%)$ & .056 \\
\hline Angiography after CABG & $67(20.2 \%)$ & $177(17 \%)$ & .218 & $52(18.4 \%)$ & $75(26.5 \%)$ & .020 \\
\hline Hospital and 30-d mortality & 0.000 & $28(2.7 \%)$ & $<.0001$ & - & - & 1.000 \\
\hline All-cause mortality & $54(16.3 \%)$ & $369(35.7 \%)$ & $<.0001$ & $48(16.9 \%)$ & $70(24.9 \%)$ & .023 \\
\hline
\end{tabular}

$R A$, Radial artery; $S V$, saphenous vein; $B M I$, body mass index; $B S A$, body surface area; $C C S$, Canadian Cardiovascular Society functional class; $L M T$, left main trunk; $T V D$, triple vessel disease; $D V D$, double vessel disease; $L A D$, left anterior descending artery; $R C A$, right coronary artery; $P D A$, posterior descending artery; $M I$, myocardial infarction; $O M$, obtuse marginal artery; $P V D$, peripheral vascular disease; $I V$, intravenous; $N T G$, nitroglycerin; $C A B G$, coronary artery bypass grafting; $C H F$, chronic heart failure; $C O P D$, chronic obstructive pulmonary disease; $P C I$, percutaneous intervention; $C P B$, cardiopulmonary bypass. *Renal failure: hemodialysis and with creatinine level greater than $2.5 \mathrm{mg} / \mathrm{dL}$.

for the SV patients, $11.5 \pm 0.3$ years (range, 10.5-12 years). The difference in the survivals between RA and SV women was $6 \%$ at 5 years $(P=.024), 12 \%$ at 10 years $(P=.022)$, and $22 \%$ at 15 years $(P=.01)$.

Table 2 shows that independent risk factors for death after CABG are older age, diabetes, congestive heart failure, ascending aorta atherosclerosis, and chronic obstructive pulmonary disease. The propensity score was included in the multivariate Cox proportional regression model to adjust for selection bias and was not found to be an independent predictor for death $(P=.6)$. Use of the RA exhibited a strong protective effect on the long-term survival with an HR of 0.64 (CI, 0.44-0.90; $P=$.017).

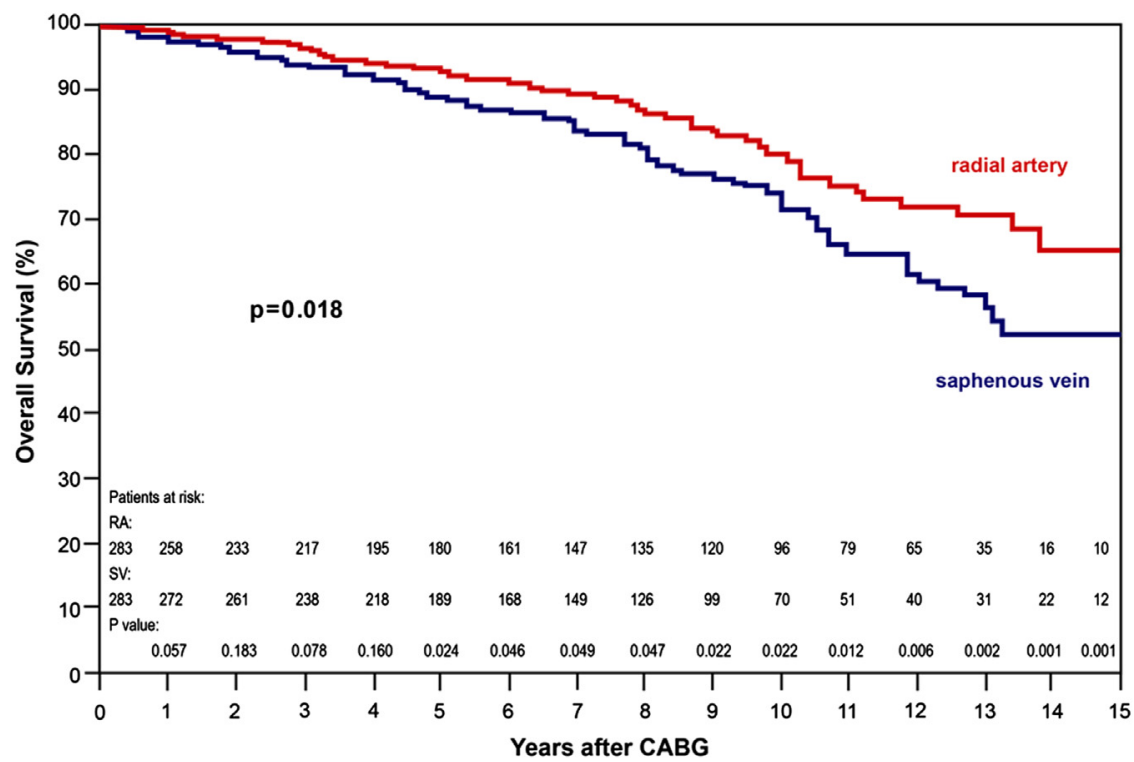

FIGURE 1. Comparison of 0- to 15-year Kaplan-Meier survival data in 566 propensity-matched women receiving left internal thoracic artery (LITA)/radial artery $(R A)$ coronary artery bypass grafting $(C A B G)$ versus LITA/saphenous vein $(S V)$ CABG. Inserted table provides the patient at risk in each group at fixed time points with the corresponding $P$ values. 
TABLE 2. Multivariate Cox proportional regression model of HRs for death in women after CABG

\begin{tabular}{lcccc}
\hline \multicolumn{1}{c}{ Variable } & HR & $\begin{array}{c}\text { Lower CI } \\
\mathbf{( 9 5} \%)\end{array}$ & $\begin{array}{c}\text { Upper CI } \\
\mathbf{( 9 5} \%)\end{array}$ & $\begin{array}{c}\boldsymbol{P} \\
\text { value }\end{array}$ \\
\hline Age $(\mathrm{y})$ & 1.11 & 1.06 & 1.17 & $<.0001$ \\
CHF & 2.71 & 1.63 & 4.50 & $<.0001$ \\
COPD & 1.84 & 1.28 & 2.65 & .001 \\
Diabetes & 1.80 & 1.22 & 2.63 & .003 \\
Ascending aorta atherosclerosis & 3.26 & 1.50 & 7.07 & .003 \\
Radial artery & 0.64 & 0.44 & 0.90 & .017 \\
\hline
\end{tabular}

$H R$, Hazard ratio; $C A B G$, coronary artery bypass grafting; $C I$, confidence interval; $C H F$, chronic heart failure; $C O P D$, chronic obstructive pulmonary disease.

\section{Graft Patency}

Of the total cohort of 1367 female patients, 244 (67 [20\%] in the RA group and 177 [17\%] patients in the SV group) had symptom-driven cardiac catheterization at our institution 0.1 to 15 years after CABG. The mean time to catheterization was $6 \pm 3.6$ years, with a median of 5.8 years. Table 3 shows angiographic patency per distal anastomosis for all conduits. Overall patency for LITA, RA, and SV grafts was $84 \%, 80 \%$, and $56 \%$, respectively. Of the 86 RA conduits, 76 were grafted to the circumflex territory, 5 to the diagonal branches of the left anterior descending coronary artery, and 5 to the right coronary artery. Of the 500 SV conduits, 200 were grafted to the circumflex, 104 to the diagonals, and 196 to the right coronary artery.

Of the 67 studied RA patients, 43 had endoscopic and 24 had open harvest of the RA. The overall RA patency was $85 \%$ (46 of 54 grafts) for the endoscopically harvested RA, which was not different from the overall patency of $72 \%$ (23 of 32 grafts) for the patients with open harvest of the RA $(P=.1)$.

Figure 2 shows the patency for LITA, RA, and SV grafts. Cox modeling showed that both LITA (HR $=0.33,95 \%$ $\mathrm{CI}=0.24-0.46 ; P<.0001)$ and RA $(\mathrm{HR}=0.38,95 \%$ $\mathrm{CI}=0.22-0.64 ; P<.0001)$ graft patencies were significantly better than SV patency. LITA and RA patency rates were similar.

\section{DISCUSSION}

The most important finding in this study is that the women who received 2 arterial conduits, the LITA and RA, had a significant survival benefit 15 years after CABG compared with women revascularized with

TABLE 3. Patency of LITA, RA, and SV conduits in 244 symptomatic patients after CABG

\begin{tabular}{lcc}
\hline \multicolumn{1}{c}{ Conduits } & Perfectly patent & Occluded or stenotic \\
\hline LITA $(\mathrm{n}=245)$ & $207 / 245(84 \%)$ & $38 / 245(16 \%)$ \\
RA $(\mathrm{n}=86)$ & $69 / 86(80 \%)$ & $17 / 86(20 \%)$ \\
SV $(\mathrm{n}=500)$ & $279 / 500(56 \%)$ & $221 / 500(44 \%)$ \\
\hline
\end{tabular}

LITA, Left internal thoracic artery; $R A$, radial artery; $S V$, saphenous vein graft; $C A B G$, coronary artery bypass grafting. the LITA and only SV. CABG with LITA/RA results in a $36 \%$ decrease in all-cause 15 -year mortality compared with traditional LITA/SV CABG in women (Table 2). Use of the RA was an independent and highly significant $(P=.017)$ predictor of improved survival in the propensity-matched groups. Women had a $12 \%$ higher rate of survival 10 years after $\mathrm{CABG}$ and a $22 \%$ higher survival at 15 years after $\mathrm{CABG}$ using RA conduit compared with only SV graft (log rank, $P=.018$; Figure 1$)$.

The use of at least 1 internal thoracic artery improves both in-hospital and long-term results after $\mathrm{CABG},{ }^{11}$ yet LITA use in women is only $50 \%$ to $75 \%,{ }^{12}$ significantly less than the $80 \%$ to $95 \%$ LITA use in men. The Society of Thoracic Surgeons National Cardiac Database ${ }^{13}$ identified female gender as an independent predictor for the nonuse of an internal thoracic artery graft. Ahmed and colleagues ${ }^{14}$ examined early and long-term results in 1114 women and 3628 men after CABG. Their adjusted hazard models for long-term all-cause mortality showed that use of the LITA and revascularization with more than 3 distal anastomoses has a protective effect on women's survival. Guru and colleagues ${ }^{15}$ showed that multiarterial grafting is associated with better long-term results in women. Yet, the use of BITA grafts in women is an infrequent occurrence. In the 4 major reports of the survival benefits of BITA grafting, women represented only $9 \%$ to $15 \%$ of the BITA patient population. ${ }^{11,16-18}$ Thus, only $50 \%$ to $75 \%$ of women receive a LITA and very few women receive more than 1 arterial conduit during CABG.

BITA grafting, especially in diabetic, obese female patients, increases the risk of sternal infection. Osteoporosis in middle-aged and elderly women may lead to sternal dehiscence, which further strongly discourages the use of BITA in women. In addition, smaller vessels in women have been suggested as a reason to avoid arterial conduit use, but there is little evidence to substantiate that position. In fact, it has been shown that LITA size is approximately equal in men and women, and women are no more likely than men to have native coronary vessels less than 1.5 $\mathrm{mm}$ in diameter. ${ }^{19}$ Surgeons have hesitated to use the RA in women owing to the fear of smaller RA caliber and spasm. In our experience, the RA is a very good size match for women's coronary vessels and RA grafts are frequently needed in patients with varicose veins. Perioperative RA spasm is rare and easily avoided with strict postoperative protocol treatment with oral nitrates and calcium-channel blockers, along with precise and injury-free endoscopic harvesting of the RA. ${ }^{8}$

Our overall RA patency in symptomatic post-CABG female patients was $80 \%$ consistent with the results published by others ${ }^{20,21}$ and our previous report of $81 \%$ in combined male and female patients. In contrast to our results, Khot and colleagues ${ }^{22}$ found an overall RA patency rate of $51 \%$ and specifically an RA patency rate of 


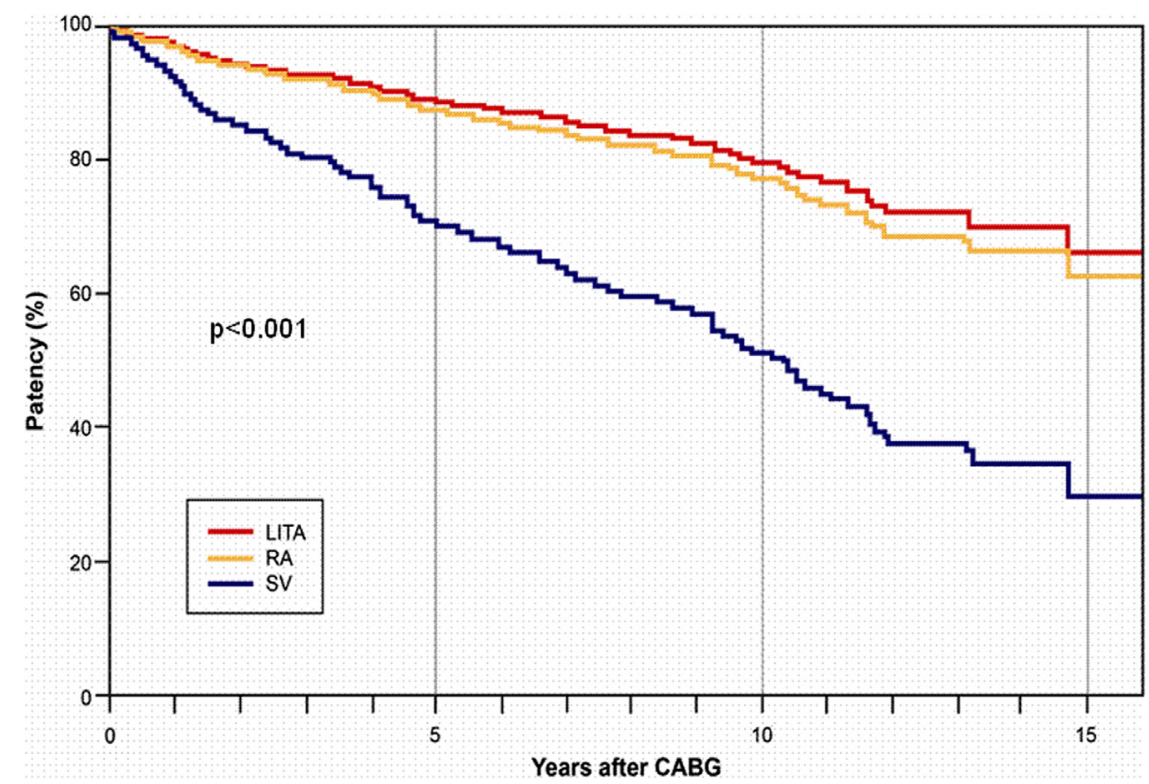

FIGURE 2. Graft patency from Cox modeling adjusting for patient clusters. LITA, Left internal thoracic artery; $R A$, radial artery; $S V$, saphenous vein grafts; $C A B G$, coronary artery bypass grafting.

only $39 \%$ in women; they concluded that the female gender is a significant predictor for RA occlusion. However, their study included a very small number of women $(17 \%)$ and had a large number $(22 \%)$ of patients undergoing redo operations mixed with patients undergoing primary CABG.

The current results from ongoing randomized trials, including the Radial Artery Versus Saphenous Vein Patency (RSVP), the Radial Artery Patency Study (RAPS), and the Radial Artery Patency and Clinical Outcomes (RAPCO), all confirm excellent patency rates (85\%-98\%) of RA grafts for both genders at 1,5 , and 10 years. ${ }^{23}$ Desai and associates ${ }^{24}$ found that RA conduits had a significantly lower occlusion rate than SV grafts at 1 year, and this effect was especially strong in women. Lawton and colleagues $^{25}$ found that, compared with SV graft recipients, women who received RA grafts had significantly improved 5-year survival, but patency rates were not reported. Our findings suggest that RA patency is similar to LITA patency and that RA patency is better than SV patency in women. This improved RA patency likely results in improved long-term survival in women undergoing CABG.

\section{Limitations}

This is an observational study, but the series represents a large, single-site, consecutive experience with standardized techniques. Preoperative, operative, and in-hospital postoperative data are derived from a mandatory, audited state database and recorded prospectively. Only patients with isolated primary CABG were analyzed. Survival data are derived from the Social Security Death Index and not from individual patient follow-up. Coronary angiography after surgery was not protocol driven, and we were able to capture only those patients who returned to our hospital for the angiogram. More RA grafts were used in patients who were younger, had no current dialysis requirement, with higher left ventricular ejection fraction, no congestive heart failure, no chronic obstructive pulmonary disease, elective surgery, and no calcified ascending aorta. The discrepant comorbid profiles were adjusted by using propensity matching.

\section{SUMMARY}

We have found that women who received 2 arterial conduits, LITA and RA, had a significant survival benefit 15 years after $\mathrm{CABG}$ compared with women revascularized with LITA and only SV. LITA/RA CABG results in a $36 \%$ decrease in risk-adjusted 15-year mortality compared with traditional LITA/SV CABG (Table 3). Use of the RA was an independent and highly significant $(P=.017)$ predictor of improved survival for women in the propensity-matched groups. RA patency is similar to LITA patency and better than SV patency, which likely results in the improved long-term survival.

\section{CONCLUSIONS}

Long-term survival after $\mathrm{CABG}$ in women is substantially improved with the use of the RA when the LITA is used to bypass the left anterior descending coronary artery. RA grafting in women should be more frequently used. 
Special thanks to our research assistants for collecting the data: Lillia Dincheva, Dana Faleck, Adam Fink, Samantha Ni, and Claire Maggiotto.

\section{References}

1. Kim C, Redberg R, Pavlic T, Eagle K. A systematic review of gender differences in mortality after coronary artery bypass graft surgery and percutaneous coronary interventions. Clin Cardiol. 2007;30:491-5.

2. Toumpoulis I, Anagnostopoulos C, Balaram S, Rokkas CK, Swistel DG, Ashton RC Jr, et al. Assessment of independent predictors for long-term mortality between women and men after coronary artery bypass grafting: are women different from men? J Thorac Cardiovasc Surg. 2006;131:343-51.

3. Tranbaugh RF, Dimitrova KR, Friedmann P, Geller CM, Harris LJ, Stelzer P, et al. Radial artery conduits improve long-term survival after coronary artery bypass grafting. Ann Thorac Surg. 2010;90:1165-72.

4. Zacharias A, Habib RH, Schwann TA, Riordan CJ, Durham SJ, Shah A. Improved survival with radial artery versus vein conduits in coronary bypass surgery with left internal thoracic artery to left anterior descending artery grafting. Circulation. 2004;109:1489-96.

5. Cohen G, Tamariz MG, Sever JY, Liaghati N, Guru V, Christakis GT, et al. The radial artery versus the saphenous vein graft in contemporary CABG: a casematched study. Ann Thorac Surg. 2001;71:180-6.

6. Caputo M, Reeves B, Marchetto G, Mahesh B, Kim K, Angelini G. Radial versus right internal thoracic artery as a second arterial conduit for coronary surgery: early and midterm outcomes. J Thorac Cardiovasc Surg. 2003;126: $39-47$.

7. Tatoulis J, Royse AG, Buxton BF, Fuller JA, Skillington PD, Goldblatt JC, et al. The radial artery in coronary surgery: a 5-year experience-clinical and angiographic results. Ann Thorac Surg. 2002;73:143-8.

8. Dimitrova KR, Hoffman DM, Geller CM, DeCastro H, Dienstag B, Tranbaugh RF. Endoscopic radial artery harvest produces equivalent and excellent midterm patency compared with open harvest. Innovations: Technol Tech Cardiothorac Vasc Surg. 2010;5:265-9.

9. Austin PC. Propensity-score matching in the cardiovascular surgery literature from 2004 to 2006: a systematic review and suggestions for improvement. J Thorac Cardiovasc Surg. 2007;134:1128-35.

10. Imai K, King G, Lau O. 2007. Zelig: everyone's statistical software, http:// GKing.harvard.edu/zelig.

11. Loop F, Lytle B, Cosgrove D, Stewart RW, Goormastic M, Williams GW, et al. Influence of the internal-mammary-artery graft on 10-year survival and other cardiac events. N Engl J Med. 1986;314:1-6.
12. Lawton JS, Brister SJ, Petro KR, Dullum M. Surgical revascularization in women: unique intraoperative factors and considerations. J Thorac Cardiovasc Surg. 2003;126:936-8.

13. Tabata M, Grab JD, Khalpey Z, Edwards FH, O'Brien SM, Cohn LH, et al. Prevalence and variability of internal mammary artery graft use in contemporary multivessel coronary artery bypass graft surgery: analysis of the Society of Thoracic Surgeons National Cardiac Database. Circulation. 2009;120:935-40.

14. Ahmed WA, Tully PJ, Baker RA, Knight JL. Survival after isolated coronary artery bypass grafting in patients with severe left ventricular dysfunction. Ann Thorac Surg. 2009;87:1106-12.

15. Guru V, Fremes SE, Austin PC, Blackstone EH, Tu JV. Gender differences in outcomes after hospital discharge from coronary artery bypass grafting. Circulation 2006;113:507-16.

16. Lytle BW, Blackstone EH, Sabik JF, Houghtaling P, Loop FD, Cosgrove DM. The effect of bilateral internal thoracic artery grafting on survival during 20 postoperative years. Ann Thorac Surg. 2004;78:2005-14.

17. Kurlansky PA, Traad EA, Dorman MJ, Galbut DL, Zucker M, Ebra G. Thirtyyear follow-up defines survival benefit for second internal mammary artery in propensity-matched groups. Ann Thorac Surg. 2010;90:101-8.

18. Tatoulis J, Buxton BF, Fuller JA. The right internal thoracic artery: the forgotten conduit-5,766 patients and 991 angiograms. Ann Thorac Surg. 2011;92:9-17.

19. Mickleborough LL, Carson S, Ivanov J. Gender differences in quality of distal vessels: effect on results of coronary artery bypass grafting. J Thorac Cardiovasc Surg. 2003;126:950-8.

20. Tatoulis J, Buxton BF, Fuller JA, Meswani M, Theodore S, Powar N, et al. Longterm patency of 1108 radial arterial-coronary angiograms over 10 years. Ann Thorac Surg. 2009;88:23-30.

21. Zacharias A, Schwann TA, Riordan CJ, Durham SJ, Shah AS, Habib RH. Late results of conventional versus all arterial revascularization based on internal thoracic and radial artery grafting. Ann Thorac Surg. 2009;87:19-26.

22. Khot UN, Friedman DT, Pettersson G, Smedira NG, Li J, Ellis SG. Radial artery bypass grafts have an increased occurrence of angiographically severe stenosis and occlusion compared with left internal mammary arteries and saphenous vein grafts. Circulation. 2004;109:2086-91.

23. Buxton BF, Raman JS, Ruejgsakulrach P, Gordon I, Rosalion A, Bellomo R, et al. Radial artery patency and clinical outcomes: five-year interim results of a randomized trial. J Thorac Cardiovasc Surg. 2003;125:1363-71.

24. Desai ND, Naylor CD, Kiss A, Cohen EA, Feder-Elituv R, Miwa S, et al. Impact of patients and target-vessel characteristics on arterial and venous bypass graft patency. Insight from randomized trial. Circulation. 2007;115:684-91.

25. Lawton JS, Barner HB, Bailey MS, Guthrie TJ, Moazami N, Pasque MK, et al Radial artery grafts in women: utilization and results. Ann Thorac Surg. 2005; 80:559-63. 